\title{
Sensitivity to ignition by electrostatic discharge of explosive dust / air
}

\author{
Dan Gabor ${ }^{1, *}$, Emilian Ghicioi ${ }^{1}$, Mihaela Părăian ${ }^{1}$, Niculina Vătavu ${ }^{1}$, Florin Adrian Păun ${ }^{1}$, \\ and Mihai Popa ${ }^{1}$ \\ ${ }^{1}$ National Institute for Research and Development in Mine Safety and Protection to Explosion - \\ INSEMEX, 32-34 G-ral Vasile Milea Street, Petroşani, 332047, Romania
}

\begin{abstract}
In industrial sectors that use, process, transport or store, substances such as combustible dusts could exist some workplaces with explosion hazard due to the possibility of dust/air explosive formation and ignition, both inside the installations and in the surrounding atmosphere. Methods and means of protection aim to prevent the development of explosive atmospheres, followed by preventing the occurrence of ignition sources and then limiting the effects of explosions. To assess the risk of ignition of the explosive atmosphere, there must be known first of all, the explosive atmosphere's sensitivity to ignition by electrostatic discharge, respectively, the minimum ignition energy of the explosive mixture, afterwards being required an analysis on the possibilities of formation and discharge of electrostatic charge. For the most common combustible dusts, the minimum ignition energy is given, but for new types of flammable substances this parameter defining the sensitivity to ignition of the mixture by electrostatic discharges must be determined. The paper presents the results of research carried out in order to develop the methods and standards for determining the minimum ignition energy of the combustible dust / air mixture and of the methods for the assessment of the risk of ignition of the dust/air explosive atmosphere by electrostatic discharge.
\end{abstract}

\section{Introduction}

Combustible dusts present a fire hazard, and in combination with air, in certain concentrations and in the presence of a source of ignition, may present an explosion hazard. The existence of this real danger was confirmed by the events that took place in various industrial units.

Dust explosions may be classified as being either "primary" or "secondary" in nature. Primary dust explosions may occur inside processing equipment or similar enclosures, and are generally controlled by relieving the pressure through purpose-built ducting to the external atmosphere. Secondary dust explosions are the result of dust accumulation inside a building being agitated and ignited by the primary explosion, resulting in a much more dangerous uncontrolled explosion that can affect the entire structure. Historically, fatalities from dust explosions have largely been the result of secondary dust explosions.

* Corresponding author: dan.gabor@insemex.ro 
For a fire to be able to burn, three things need to occur simultaneously: Fuel, Ignition, and Oxygen. In the absence of any one of these and you cannot have a fire. In fire safety this idea is known as the "Fire Triangle", and is commonly used to help avoid industrial fires [1].

To understand a combustible dust explosion though, two more elements need to be added to the fire triangle to create the "Dust Explosion Pentagon" (Figure 1). The two new elements are Confinement and Dispersion. These elements are created when the fuel, in this case combustible dust, is spread out as a dust cloud within a closed area, such as a factory or warehouse. Much like with the fire triangle, taking away even one of these elements can remove the risk of a dust explosion; however, the risk for a fire can still be present [1].

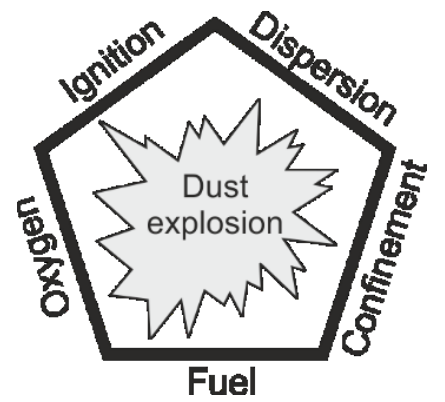

Fig. 1. Dust Explosion Pentagon.

A dust explosion can result in:

- death or serious injury of workers,

- destruction of facilities/installations and buildings,

- secondary explosions,

- fire.

Since, in most cases, fires and explosions cause damages with significant economic and social effects, appropriate measures must be taken to prevent such a hazard. These measures aim to prevent the formation of explosive atmospheres, preventing the occurrence of sources of ignition and limiting the effects of explosions.

One of the many sources of ignition of the potentially explosive dust/air atmosphere is static electricity. Electrostatic charges are quite common in many industrial processes or activities.

The critical factor in assessing hazards generated by electrostatic charging is the probability that a potentially explosive dust / air atmosphere and a dangerous electrostatic charge are present at the same time and place. This probability is significantly high when handling a dust product because it can lead to both dangerous charging (of an equipment / object or of a person) and the formation of a potentially explosive dust / air atmosphere. In particular, this may occur during the handling of non-conductive bulk powders. However, even conductive dusts can accumulate high charges if they are processed in non-conductive equipment. High electrostatic charges may also occur in non-conductive or non-earthed installations.

Under certain conditions, electrostatic charges generated by some parts of installations or by materials / processes can be accumulated and then discharged, hence generating energies high enough to ignite a dust / air explosive atmosphere.

Static electricity discharges vary widely in type and degree of ignition potential.

Assessing the occurrence and incendivity (the ability to ignite) of electrostatic discharge in various real-life situations is the most important and most difficult step. A synthesis of the ignition capacity (incendivity) of the different types of discharges that occur in practice can be found in Table 1. 
As resulting from Table 1 below, there are only two types of discharges, (i.e. corona and brush discharge), that are not able to cause the ignition of an explosive dust / air atmosphere.

Table 1. Synthesis of initiation capacity by type of discharge [2].

\begin{tabular}{|c|c|c|c|}
\hline \multirow{2}{*}{ Type of discharge } & \multicolumn{3}{|c|}{ Incendivity } \\
\cline { 2 - 4 } & \multicolumn{2}{|c|}{ Gases, Vapours } & \multirow{2}{*}{ Dust } \\
\cline { 2 - 4 } & $\begin{array}{c}\text { MIE }< \\
0.025 \mathrm{~mJ}\end{array}$ & $\begin{array}{c}\text { MIE }> \\
0.025 \mathrm{~mJ}\end{array}$ & \\
\hline Spark discharge & + & + & + \\
\hline Corona discharge & + & - & - \\
\hline Brush discharge & + & + & - \\
\hline Propagating brush discharge & + & + & + \\
\hline Cone discharge & + & + & ++ \\
\hline Lightning discharges & + & + & + \\
\hline
\end{tabular}

The ignition hazards caused by electrostatic charges were addressed in many books, guidelines, guides and other publications, but so far, they have not been included in an European standard, such standard has been in the drafting process for many years [3-7]. More specifically, the process for adopting such standard started in 1999, when a document called CENELEC TC 44X Draft R004-001 - February 1999 "Safety of machinery Guidance and recommendations for the avoidance of hazards due to static electricity" was drafted. However, the standard was not finalized.

This document has undergone several phases. The first phase was the prEN August 2002 document CENELEC TC 31 (sec) 388 "Electrostatics. Code of practice for the avoidance of hazards due to static electricity", followed by CLC / TR 50404 June 2003" Electrostatics - Code of practice for the avoidance of hazards due to static electricity"), while the last phase which is ongoing consists of a Report Technical IEC 60079-32 TS Edition 1.0: Explosive atmospheres - Electrostatics with two parts: Part 32-1: Guidance and Part 32-2: Tests.

\section{Assessing the risk of ignition for dust $/$ air explosive atmosphere considering the sensitivity to ignition, namely the minimum ignition energy (MIE)}

The minimum ignition energy (MIE) of the explosive dust / air mixture is a parameter that defines the sensitivity of the mixture to ignition and it is essential for assessing the risk of ignition of the potentially explosive dust / air atmosphere by electrostatic discharges.

The first step in order to assess the risk of an explosive atmosphere being ignited is to determine the sensitivity of the explosive atmosphere to ignition by means of an electrostatic discharge, i.e. the minimum ignition energy (MIE) of the explosive mixture. Afterwards, an analysis of the charging possibilities and electrostatic discharge should be performed.

For correctly assessing the risk of explosion, the probability of the formation of charges and discharges for both equipment and products (materials) must be taken into consideration. The data required for a correct assessment are:

- precise information on the characteristics of the potentially explosive mixture that can be formed,

- resistance or conductivity of the substances, equipment, packaging, materials and personal protective equipment used,

- volumes and geometric arrangement of installations and technical devices, 
- precise information on existing grounding conditions and potential equilibrium conditions.

Steps leading to the ignition of a potentially explosive atmosphere by the electrostatic discharges are shown in Figure 2 [2].

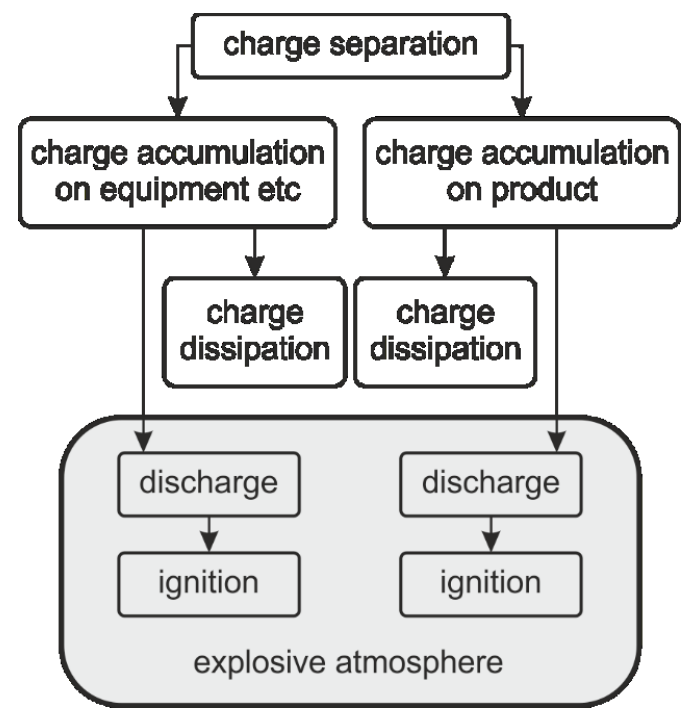

Fig. 2. Chart containing the steps leading to the ignition of a potentially explosive atmosphere for electrostatic charges and discharges [2].

If the incendivity of the discharge (i.e. the released amount of energy) and the sensitivity of the existing potentially explosive atmosphere, are known factors, as characterized by the minimum ignition energy MIE, it can be determined whether the ignition occurs or not.

For the most common flammable dusts, the minimum ignition energy is specified in the technical specifications or in some databases; however, new types of flammable substances in dust form occur often and for such the MIE parameter must be determined, (this parameter defines the sensitivity of the mixture to ignition by electrostatic discharge).

Although there are several methods for determining the minimum ignition energy, in order to perform a unitary assessment in accordance with ATEx Directives (Directive 2014/34 / EU and Directive 1999/92 / EC), standardized European methods should be used.

Figures 3 and 4 illustrate two logical diagrams used to evaluate bulk material with a conductivity of $1 \mathrm{M} \Omega \cdot \mathrm{m} \ldots 10 \mathrm{G} \Omega \cdot \mathrm{m}$ and above $10 \mathrm{G} \Omega \cdot \mathrm{m}$. In both evaluations described by these diagrams it is necessary to know the minimum ignition energy of the dust / air mixture [8] 


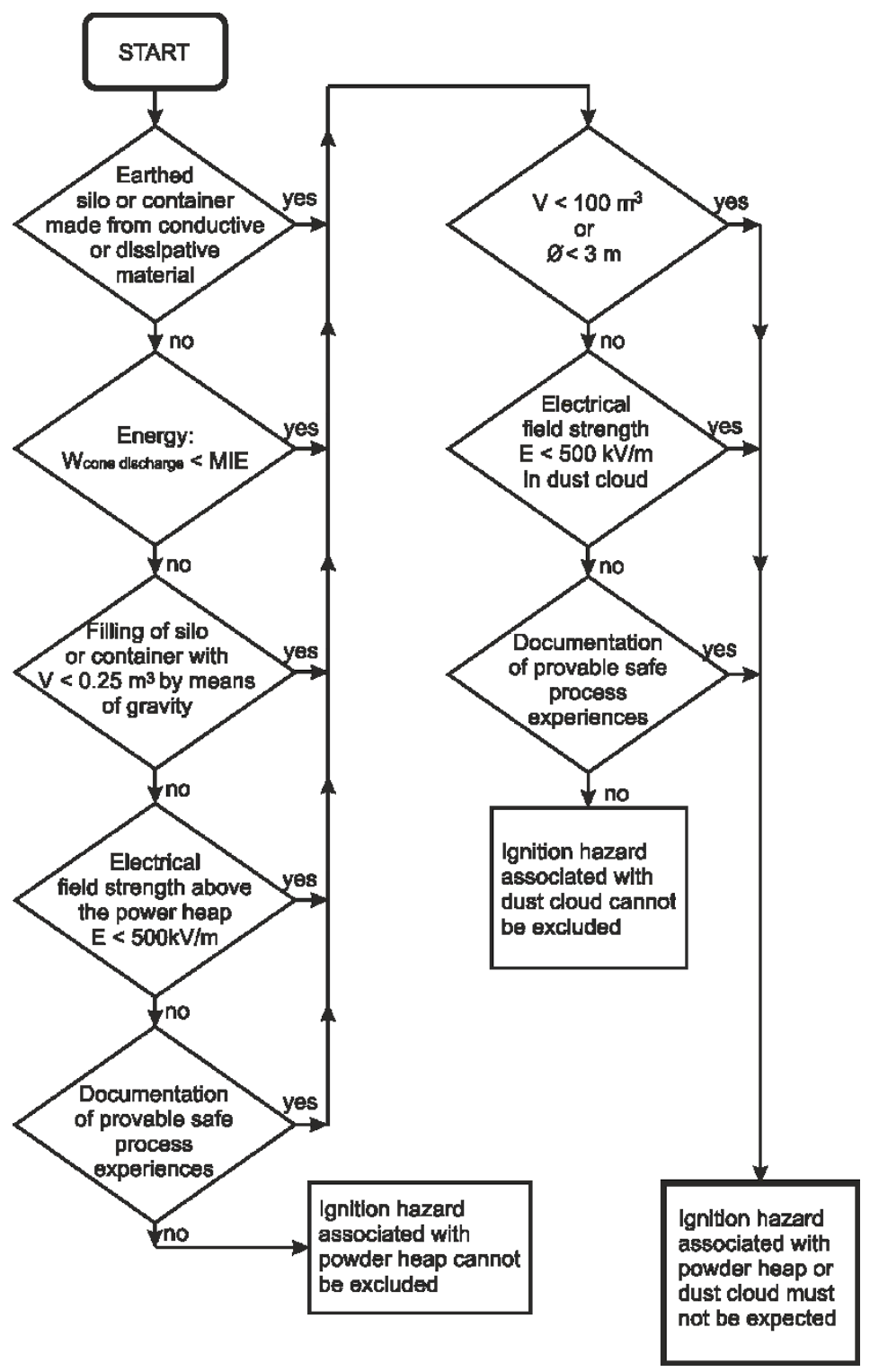

Fig. 3. Assessment of bulk material with conductivity of $1 \mathrm{M} \Omega \mathrm{m}<\rho \leq 10 \mathrm{G} \Omega \mathrm{m}[8]$

When assessing the risk of explosion of dust / air explosive atmospheres, all factors that may influence the occurrence of the actual ignition source must be taken into consideration. For example, the assessment of the risk of ignition through electrostatic discharges in a silo should consider not only the ignition sensitivity of the mixture (MIE), but also the conductivity of the material, the volume and diameter of the silo, as well as the penetration strength of the electric field. 


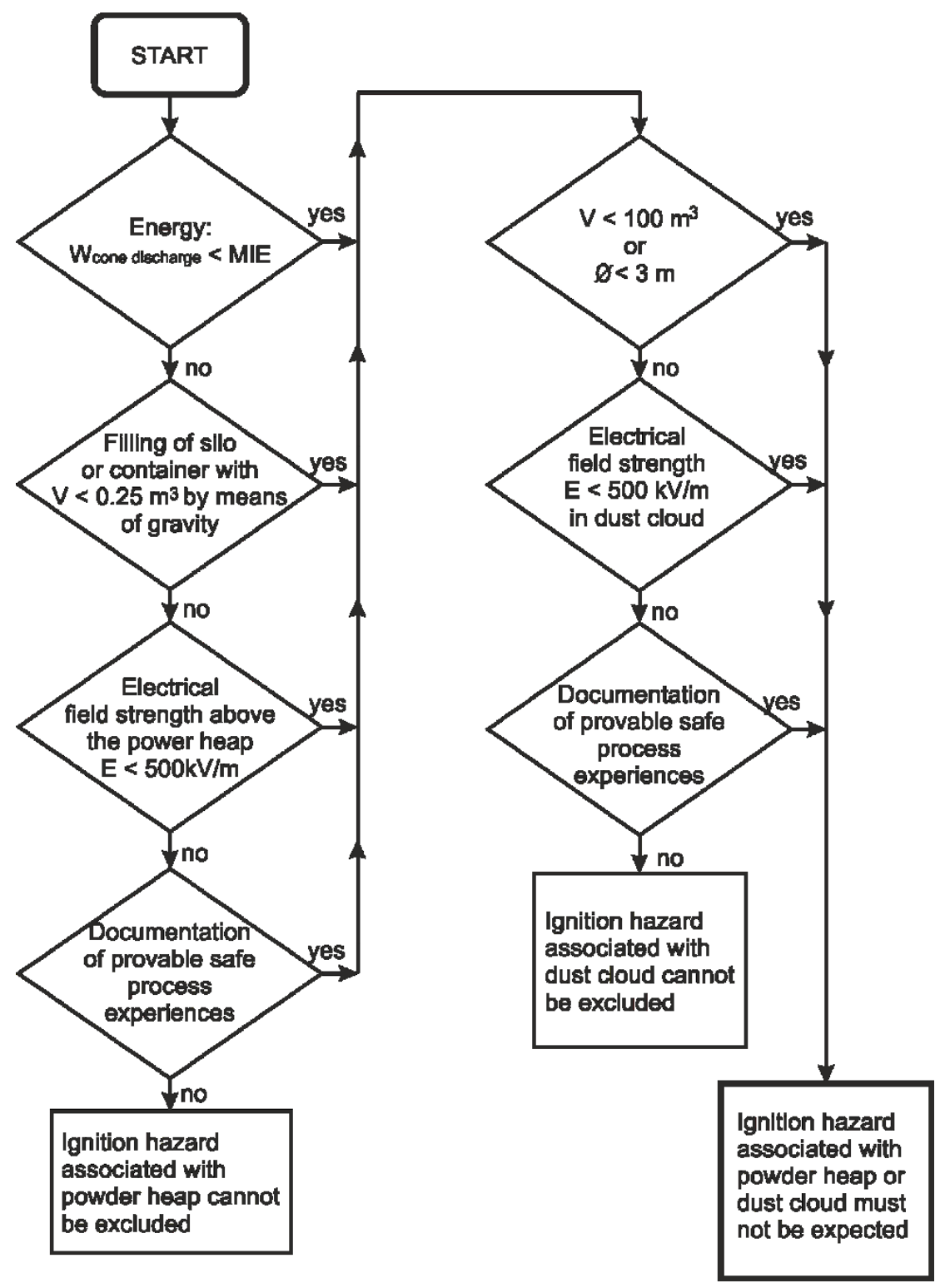

Fig. 4. Assessment of bulk material with conductivity $\rho>10 \mathrm{G} \Omega \mathrm{m}[8]$

In conclusion, the risk of explosion assessment is performed to ensure the safety and health of workers and goods from industries dealing with the processing, storing or transport of substances in the form of flammable powders.

Analysis of the risk of explosion is performed to determine protective measures against the ignition of potentially explosive atmospheres. 


\section{Methods for determining minimum ignition energy (MIE)}

The EN 80079-20-2 standard defines MIE as the lowest energy accumulation on a capacitor and which is sufficient to cause ignition of the lightest dust mixtures under the specified test conditions.

Methods for the determination of the minimum ignition energy may be estimative methods or quantitative methods as set out in IEC 61241-2-3: 1994, EN 13821: 2003 and EN 80079-20-2. In 2016, the previous standard EN 13821: 2003 was replaced by standard EN 80079-20-2: 2016. In the new standard the only accepted method being the quantitative one using the modified Hartmann tube.

The minimum ignition energy for dust / air mixtures varies depending on certain parameters, such as: the particle size distribution, the moisture / solvent content, as well as the testing method / equipment used.

In the laboratories of the National Institute for Research and Development in Mine Safety and Protection to Explosion - INSEMEX from Romania, the minimum ignition energy of explosive dust / air mixtures can be determined by both methods, more specifically:

- Estimation method using a 201 test cell (vessel) based on which only an estimated value of the minimum ignition energy can be determined.

- Quantitative method using modified Hartmann tube which provides more accurate values for the minimum ignition energy.

Due to the fact that the estimation method is outdated, INCD Insemex acquired in 2018 a complex equipment to determine the minimum ignition energy of explosive dust / air mixtures based on the quantitative determination method (Figure 5).

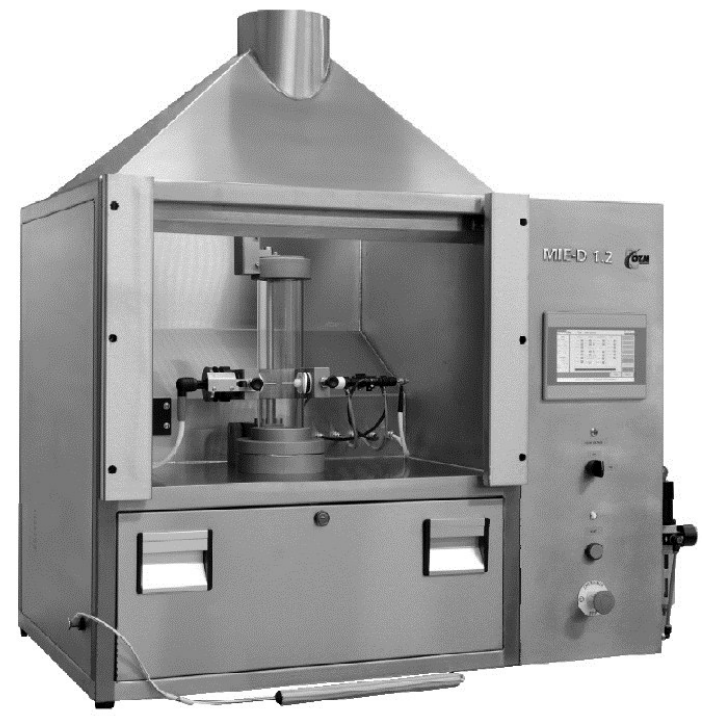

Fig.5 - MIE-D 1.2 equipment produced by OZM Research from Czech Republic to determine the minimum ignition energy of dust / air mixtures [9]

This equipment for MIE determination allows for the start time and dust concentration to be changed so as to determine the most suitable conditions for the explosion.

Research has shown that the explosion of dust is influenced by several basic parameters [9], among which:

- Delay between dust dispersion and spark production, 
- The method of dispersing the powder which is influenced by the size and shape of the dispersion nozzle,

- The characteristics of the spark, i.e. duration and energy which are influenced by the electric circuit design, by the values of capacitance, inductance and resistance,

- The amount of dust and the particle size distribution of the dust placed in the lower part of the explosion chamber before the experiment.

These parameters are identified and described in detail by Eckhoff in his book [10] and afterwards quoted by other authors, for example, by S. Bernard [8]. Such literature qualifies the delay between the time of the dispersion of the dust and the moment of ignition as a very important parameter [11]. According to R. K. Eckhoff [10], the level of turbulence decreases as the delay is higher.

The relationship between MIE and delay is shown in Figure 6 [10].

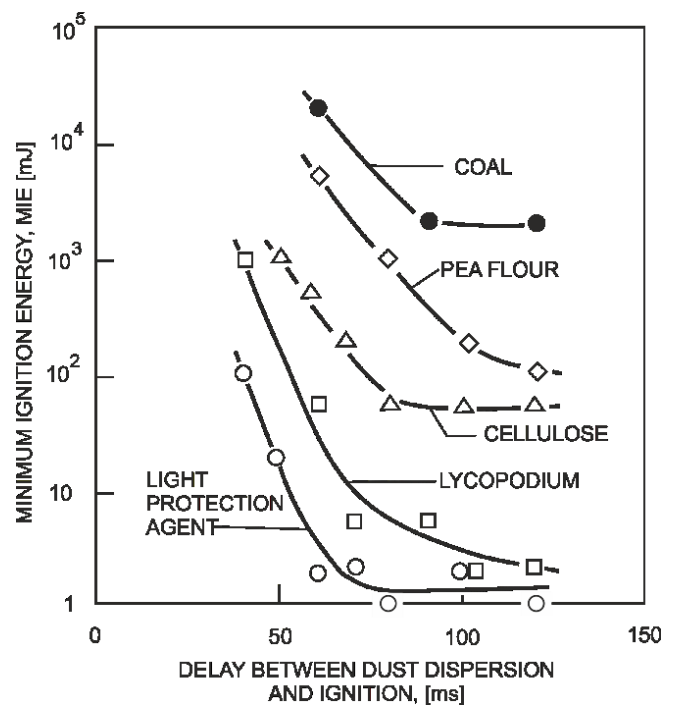

Fig.6 - Effect of Initial Turbulence of Explosive Dust Cloud on Minimum Energy Required for Spark Ignition [10]

\subsection{Description of the equipment for determining minimum ignition energy of an explosive mixture of dust / air}

The equipment for determining the minimum ignition energy of explosive dust / air mixtures consists of seven basic subassemblies (Figure 7):

- Hartmann glass tube with handling unit,

- High voltage unit,

- Dust dispersing system,

- Electronic and pneumatic instrument control,

- Control panel with touch screen,

- Instrument case,

- PC with installed test guide. 


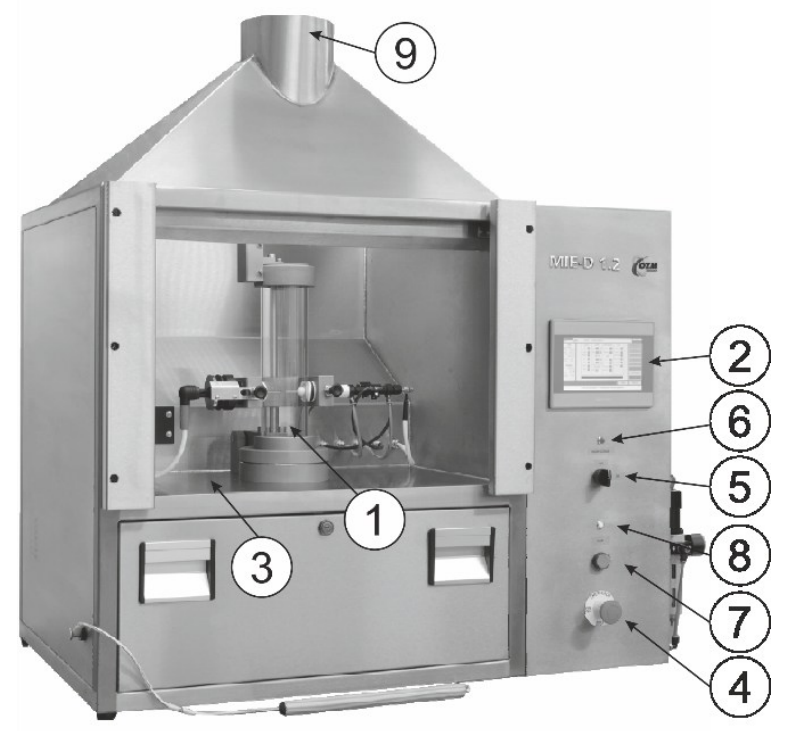

Fig. 7. Presentation of the equipment components (front view): 1. Hartmann glass tube; 2. Control panel; 3. Sliding door equipped with a closed-position safety sensor; 4. Emergency stop button; 5 . High voltage switch; 6 . High voltage presence indicator; 7. Start button; 8 . Function indicator; 9 Outlet for exhaust fumes [10]

The logic operating diagram of the equipment for determining the minimum ignition energy is shown in Figure 8.

In accordance with the requirements and recommendations of EN 80079-20-2: 2016, dust dispersion and mixture ignition take place in a Hartmann tube with a capacity of 1.2 litres.

The dust deposited at the base of the Hartmann tube is dispersed by a compressed air stream, air released from a $50 \mathrm{ml}$ tank of a dispersion system with electro-pneumatic valves. The tank contains compressed air at a pressure of 7 bar $(700 \mathrm{kPa})$.

The electrostatic discharge is generated in the high voltage unit. The unit consists of a high voltage source, a set of internal capacitors, a high voltage switch, a discharge circuit, high voltage electrodes and electro-pneumatic valves for switching capacitors and measuring modes.

Both dust and high voltage systems are controlled by a Programmable Logic Controller (PLC), which communicates with the operator through the touch screen control panel. With the exception of the control panel, the entire system is located in the booth casing. The clear acrylic glass door, equipped with a closed-position safety sensor, protects the operator and at the same time enables the user to follow the course of the experiment to see if the ignition has occurred.

The MIE-D Lab program guides the user throughout the experiment and also provides an evaluation and archiving of the data obtained. The program is installed on a separate computer, thus eliminating the influence of common operating systems (for example, Windows) on the control program running on the PLC device and thus increasing the safety of operation. Sample preparation is also not connected to the device itself. 


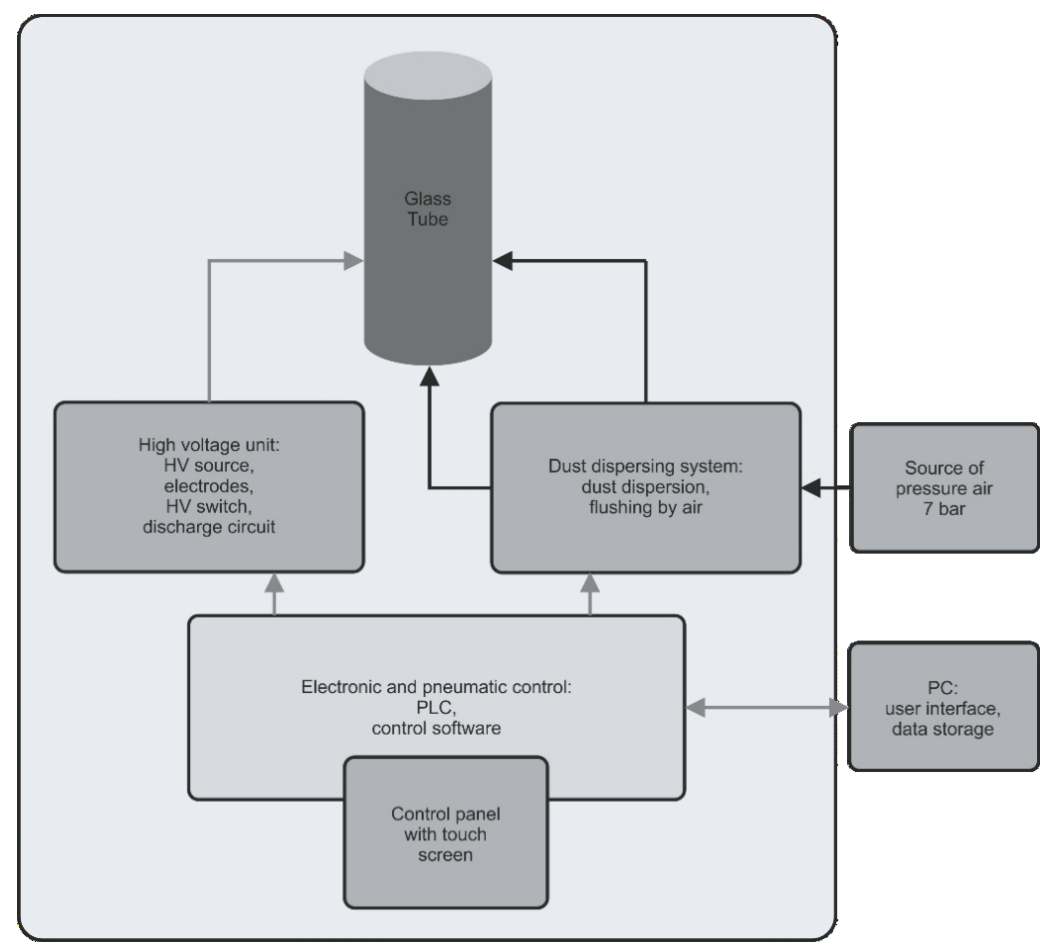

Fig. 8. Logical operating scheme for equipment to determine the minimum ignition energy of explosive dust / air mixtures [7]

The MIE-D 1.2 booth has a special feature that distinguishes it from other equipment's for determining the MIE, namely that it has a module for measuring the actual energy that is supplied to the discharge electrodes. This energy is different from the nominal energy $\mathrm{E}$ $=0.5 \mathrm{C} \cdot \mathrm{U} 2$, and can be measured with this module. According to the manufacturers of this equipment (OZM Research), for example, for a nominal energy selected at $\mathrm{E}=2 \mathrm{~J}$, an energy equal to $0,88 \mathrm{~J}$ will be supplied to the electrodes and only an energy of $0,28 \mathrm{~J}$ will be dissipated as heat and which can initiate the ignition of the dust / air mixture $[12,13]$.

\section{Results}

The ignition sensitivity by electrostatic discharge of explosive dust / air mixtures is an important parameter in assessing the risk of ignition of a dust / air explosive atmosphere. MIE.

The ignition sensitivity can be assessed by determining the minimum ignition energy

The standardized method for determining minimum ignition energy according to EN 80079-20-2: 2016 uses dust dispersion and ignition of the mixture in a Hartmann tube with a capacity of 1.2 litres. For ignition an electric spark is generated between two electrodes, a spark whose rated energy is calculated as $\mathrm{E}=0.5 \mathrm{C} \cdot \mathrm{U} 2$, where $\mathrm{C}$ is the value of the storage capacitor and $\mathrm{U}$ is the voltage value at the capacitor terminals.

According to the latest research, it has been found that the real spark energy is less than the nominal energy and we believe that it is necessary to revise the EN 80079-20-2: 2016 standard by replacing the existing method with one that provides a true value of the ignition energy. 


\section{Summary of Findings}

Research conducted at INCD INSEMEX laboratories showed that the current MIE determination methods for dust / air explosive mixtures require improvements. The improvements which we believe to be made is shown in this work, as follows: generate a spark during the tests and determine the energy of the real value.

Continuing research by comparing the results obtained by the two methods for determining the MIE (estimated and quantitative) for different dust / air mixtures has been found that for a particular type of combustible dust results can be totally different. For example, in the case of tobacco dust, the combustible dust, using the estimated method, obtained an MIE value of $0.1 \div 1 \mathrm{~J}$ but using the quantitative method with the modified Hartmann tube even at an energy value of $3 \mathrm{~J}$ the dust / air mixture could not have been initiated. The causes of these differences have not yet been determined, research continues.

\section{References}

1. M. Glor, P. Thurnherr, Ignition Hazards Caused by Electrostatic Charges in Industrial Processes (Thuba, 2015)

2. A. Janes, J. Chaineaux, D. Carson, P. A. Le Lore, Journal of Hazardous Materials, 152, 32-39 (2008)

3. ISO, EN ISO 80079-36:2016 (2016)

4. European Parliament, European Council, Directive 2014/34/EU (2014)

5. European Parliament, European Council, Directive 1999/92/EC (1999)

6. Hughes Environmental, Understanding the Dust Explosion Pentagon, available at https://hughesenv.com/understanding-dust-explosion-pentagon/ (2015)

7. International Electrotechnical Commission, IEC TS 60079-32-1:2013 (2013)

8. S. Bernard, K. Lebecki, P. Gillard, L Youinou, G. Baudry, Journal of Loss Prevention in the Process Industries, 23, 3, 404-411 (2010)

9. B. Janovsky, M. Macenaue, Manual MIE-D 1.2 Apparatus for determining the minimum ignition energy of dust dispersions (OZM Research s.r.o, Hrochuv Tynec, Czech Republic)

10. R. K. Eckhoff, Explosion hazards in the process industries (Gulf Publishing Company, 2005)

11. J. Cupak, B. Janovsky, J. Vojtech, Measurement of the energy balance in the spark igniting the dust dispersion, OZM Research, Poster Abstract, 9th International Seminar on Fire and Explosion Hazards (2019)

12. European Standards, EN 1127-1:2011 (2011)

13. International Electrotechnical Commission, IEC 60079-0:2017 (2017) 